\title{
DIAKRONIKA
}

Vol. 17 No. 2 Th. 2017 p: 118-141

ISSN: 1411-1764 (Print) | 2620-9446 (Online)

http://diakronika.ppj.unp.ac.id

\section{Tuanku Nan Renceh (1762-1832)}

\author{
Irwan Setiawan \\ irwansetiawan81@gmail.com \\ Smk Negeri 1 Baso
}

\begin{abstract}
Tuanku Nan Renceh was an Islamic cleric (ulama), leader and commanding figure who held in Indonesia History as a fighter against the Dutch colonialism in the battle known as the Padri War in Minangkabau. In contrast to this, the existence of this figure in history, was generally considered as a controversial figure who was responsible for the violence and bloodshed. Ironically, this figure appeared as a completely controversial figure on account of the written sources generally referred to him as an emotionally charged, fierce and frightening character. The source came from the enemy of Tuanku Nan Renceh at that time. When searching about his biography, it was very rarely obtained information about the history of life, family, struggle and the end of his life. The recent short article revealed the life history of Tuanku Nan Renceh and his valuable contribution for Minangkabau history in the days of Padri. Through this formulated paper, it is expected the life history of Tuanku Nan Renceh can be discovered. Most importantly, the respected readers can also assess his presence in more neutral position and do not discredit his character as a radical figure.
\end{abstract}

Keywords: Biography, Tuanku Nan Renceh, Paderi, Minangkabau

\begin{abstract}
Abstrak
Tuanku Nan Renceh adalah nama tokoh yang sering muncul dalam pembahasan sejarah perang Paderi di Minangkabau. Namun keberadaan sosok ini dalam sejarah, umumnya dinilai sebagai tokoh kontroversial yang memunculkan perselisihan dan pertumpahan darah. Tokoh ini muncul sebagai tokoh yang penuh kontroversial dikarenakan sumber-sumber tertulis yang ada umumnya menyebut beliau sebagai tokoh yang penuh emosional, garang dan menakutkan. Sumber itu berasal dari pihak lawan Tuanku Nan Renceh pada masa itu. Bila dilakukan pencarian tentang biografi beliau sangat jarang didapatkan informasi tentang sejarah hidup, keluarga, perjuangan dan akhir hayatnya. Tulisan singkat ini mengungkap sejarah hidup Tuanku Nan Renceh dan tindak tanduknya dalam sejarah Minangkabau di zaman Paderi. Dengan adanya tulisan ini diharapkan dapat diketahui sejarah hidup Tuanku Nan Renceh. Para pembaca juga dapat menilai keberadaan Tuanku Nan Renceh dalam posisi yang lebih netral dan tidak mendeskreditkan tokoh ini sebagai tokoh radikal.
\end{abstract}

Kata Kunci : Biografi, Tuanku Nan Renceh, Paderi, Minangkabau 


\section{Pendahuluan}

Sosok Tuanku Nan Renceh tidak sejelas namanya sebagaimana yang sering disebut dalam buku sejarah. Tuanku Nan Renceh sangat sering digambarkan sebagai sosok yang kontroversial khususnya dalam sejarah Minangkabau. Tuanku Nan Renceh adalah seorang putra kelahiran daerah Kamang kabupaten Agam. Perawakan Tuanku Nan Renceh bertubuh kecil. Beliau diyakini pula sebagai salah seorang tokoh proklamator dan lokomotif utama gerakan Paderi pada awal abad ke-XIX silam. Meski banyak hal yang membuat namanya begitu terkenal, namun untuk sejarah dan biografinya masih sulit ditemukan. Penulis berinisiatif untuk meneliti dan mengkaji biografi singkat tentang Tuanku Nan Renceh.

Penelitian ini mampu memberi manfaat terutama bagi pembaca agar mengetahui kehidupan sosok seorang tokoh bernama Tuanku Nan Renceh. Kajian ini membahas perihal tindak tanduk Tuanku Nan Renceh semasa hidupnya. Penulis berharap melalui tulisan ini kiranya dapat diperbaiki citra negatif yang selama ini melekat pada tindakan-tindakan kelompok Paderi, khusunya Tuanku Nan Renceh.

Usaha penulis untuk mempelajari dan memahami tentang Tuanku Nan Renceh telah dirintis sejak tahun 2012. Bahan-bahan terkait tentang sejarah Tuanku Nan Renceh mulai penulis cari dari masyarakat Kamang. Usaha itu diupayakan untuk menerapkan metode sejarah lisan dengan cara bertanya kepada para tokoh-tokoh masyarakat Kamang.

Penulis melakukan pencarian bahan dan sumber berupa tulisan dan buku tentang tokoh Tuanku Nan Renceh dari berbagai bahan pustaka dan pencaharian ke toko-toko buku yang ada di Sumatera Barat. Untuk memperkaya informasi mengenai Tuanku Nan Renceh penulis mencari data dan informasi dari para informan, pakar sejarah, serta dosen sejarah di Universitas Negeri Padang, Universitas Andalas dan Balai Pelestarian dan Nilai Tradisional Padang.

Informasi tentang tokoh Tuanku Nan Renceh juga penulis dapatkan dari bahan di internet yang banyak beredar dan telah menjadi perbincangan. Dari proses itu terkumpul sumber tertulis dan sumber lisan tentang sosok Tuanku Nan Renceh dan Perang Paderi yang kemudian penulis olah menjadi tulisan ini.

\section{Metode}

Sumber utama yang menjadi acuan penulisan ini adalah bahan dengan kategori sumber primer yaitu Naskah-naskah tantang Tuanku Imam Bonjol yang dicetak ulang oleh Lembaga Kajian Paderi 1808-1838. Sumber primer 
lainya adalah tulisan Fakih Saghir dengan karyanya Surat Keterangan Syekh Jalaluddin. Buku ini tidak penulis miliki secara utuh, namun sebagian isinya ditemukan di internet. Untuk pembahasan Tuanku Nan Renceh pada kedua bahan ini masih minim sehingga harus diperkaya dengan sumber sekunder lainnya.

Untuk memperkaya informasi tentang Tuanku Nan Renceh penulis menggunakan buku dan tulisan dengan kategori sumber sekunder. Sumber sekunder yang gunakan diantaranya tulisan (Ahmad Dt Batuah, 1957): Tambo Minangkabau, Rusli Amran Sumatera Barat Hingga Plakat Panjang, Bachtiar Chamsyah, Ismael Hassan, dkk Gerakan Paderi Pahlawan dan Dendam Sejarah (Bachtiar Chamsyah, Ismael Hassan, 2009), Christine Dobbin, Manifestation De L'islam, Islamic Fervour as a Manifestation of Regional Personality in Colonial Indonesia: The Kamang Area, West Sumatra, 1803-1908 (Dobbin, 1998). Tulisan Christine Dobbin lainnya, Gejolak Ekonomi, Kebangkitan Islam dan Gerakan Paderi Minangkabau 1784-1847(Dobbin, 2008). Ada juga tulisan Hamka Dari Perbendaharaan Lama, dan Jeffrey Hadler Sengketa Tiada Putus "Matriakat, Reformasi Agama, dan Kolonialisme di Minangkabau" (Hadler, Berlian, \& Abdullah, 2010; Hamka, 1963)

Tulisan yang memicu kontroversi seperti karya Mangaradja Onggang Parlindungan, dengan sebuah judul Pongkinangolngolan Sinambela gelar Tuanku Rao: terror agama Islam Mazhab Hambali di Tanah Batak, 1816-1833 juga penulis rujuk untuk membuat tulisan (Onggang, 1964). Proses pengumpulan bahan atau tahap heuristik yang telah penulis lakukan ditemukan 15 sumber tertulis berupa buku dan artikel ilmiah. Sedangkan bahan dari sumber internet ditemukan lebih kurang delapan berita web tentang tokoh Tuanku Nan Renceh.

Tahap selanjutnya, dilakukan pengumpulan sumber, pelaksanaan kritik sumber. Kritik terhadap bahan yang telah dikumpulkan penulis lakukan dengan memilih dan menentukan bahan yang akan dipakai dalam penelitian. Penelitian biografi Tuanku Nan Renceh ini diperkaya dengan pemanfaatan metode sejarah lisan.

Tahap ketiga proses penelitian tahap interpretasi. Sumber-sumber yang telah lolos seleksi melalui kritik sumber kemudian dianalisis sehingga memunculkan data-data, akhirnya mendapatkan fakta-fakta sejarah, dan rangkaian peristiwa sejarah hidup dan biografi Tuanku Nan Renceh. Rangkaian data dan fakta yang ditemukan kemudian dirangkum dalam bentuk tulisan.

Historiografi adalah tahap akhir dilakukan dalam proses penelitian sejarah. Jadi dari bahan yang ada dan telah lolos seleksi serta telah dapat menggambarkan alur sejarah dan fakta sejarah kemudian penulis ungkapkan dalam tulisan ini. 


\section{Hasil Dan Pembahasan}

Secara bertahap, dari abad XVI, Islam datang dari Aceh, Pariaman dan menembus nagari di Minangkabau. Sementara itu dari jalur lain Islam juga masuk dari daerah Siak-Riau dan menjalar ke wilayah pedalaman Minangkabau. Islam merasuk dalam kehidupan masyarakat Minangkabau. Pendalaman agama Islam berawal dari surau. Surau dianggap seperti rumah bagi pemuda Minangkabau. Pemuda minangkabau umumnya tinggal di surau perkampungan mereka. Rumah pada umumnya diperuntukkan sebagai tempat tinggal bagi kaum perempuan, sumando (suami dari kakak perempuan), orang tua dan anak-anak.

Murid-murid (para pemuda) yang mengaji di surau umumnya belajar ilmu agama. Ada juga murid di surau yang menulis buku berbahasa Arab. Buku itu berisi cara yang benar dalam berdoa, dan beribadah. Hal penting lainnya adalah bahwa semua murid harus membantu tuanku (tokoh dan guru agama) untuk mengolah sawah dan ladangnya. Dalam keseharian para murid sangat tergantung pada sedekah dari masyarakat yang diserahkan pada tuanku.

Hal ini memunculkan ikatan emosional yang mendalam antara tuanku dan murid-muridnya. Sejumlah surau di Kamang telah menerapkan hal seperti itu. Pada surau-surau di Kamang murid-murid secara kolektif didorong untuk menata hidup dengan gaya hidup Islam.Sejak abad XVIII kopi menjadi primadona ekspor yang banyak terdapat di darek. Hasil perekonomian yang melimpah memberi pengaruh terhadap munculnya masyarakat yang makmur secara ekonomi. Di sisi lain muncul kelompok-kelompok para perampok atau penyamun yang berkeliaran di beberapa daerah. Mereka mengincar tempat-tempat yang lengang antar nagaribahkan di perbukitan.

Konflik (perkelahian) sering terjadi. Penyelesaiannya dilakukan oleh ulama. Dengan demikian kekuatan dan pengaruh ulama makin luas baik di nagari maupun lintas nagari. Hal ini berbeda dengan kekuatan para penghulu yang terbatas pada suatu nagari dan kaumnya saja.

Sejak akhir abad ke XVIII dan berlanjut keabad XIX perdagangan kopi di Sumatera makin maju, hal ini dapat dilihat dari catatan perdagangan kopi di Padang. Tahun 1803 catatan penjualan kopi di dua buah kapal dagang, satu kapal dagang membawa 10.460 pon kopi, dan kapal dagang lainnya membawa 425.000 pon kopi. Harga kopi ditahun 1800, untuk 1 pikul adalah f.7 (gulden), terus naik ke f.10 bahkan mencapai f.20. Pada tahun 1820 sampai 1822 harga kopi per pikulnya bahkan menembus f.30 dan f.40. Inilah dampak dari digemarinya kopi di Eropa, mereka menyatakan "tidak ada harga yang tinggi bagi mereka untuk mendapatkan kopi”. Hal ini membawa 
peningkatan ekonomi bagi masyarakat Minangkabau, termasuk Kamang yang juga merupakan daerah penghasil kopi terpenting di darek Minangkabau.

Daerah Kamang terletak 12 kilometer sebelah timur dari Fort De Kock (Bukittinggi). Masyarakat daerah Kamang umumnya hidup sebagai petani. Sawah yang luas dan tanaman berharga seperti tebu, bawang, kentang, kopi dan cassia (kulit kayu manis) banyak ditemukan di daerah ini. Kemajuan ekonomi Kamang telah tergambar sejak pertengahan abad XVIII. Hal itu dapat dibaca dari penjelasan Christine Dobbin berikut (Dobbin, 2008).

Kamang-Bukik mengalami per-kembangan ekonomi di akhir abad ke delapan belas melalui permintaan dunia untuk kopi dan kulit kayu manis. Dari tahun 1740-an bangsa Eropa membutuhkan kulit kayu manis, berlanjut dengan permintaan masyarakat dunia tahun 1790 untuk mendapatkan biji kopi, hasilnya dalam masyarakat berebut me-nanam kulit kayu manis dan kopi di Minangkabau khusus-nya di Kamang.

Pada abad ke XIX setidaknya ada 12 nagari (desa di Minangkabau) terdapat di daerah ini. Sejarah Kelarasan Kamang mulai tercatat sejak tahun 1833 saat peran Belanda di Fort De Kock makin besar. Belanda memperkenalkan sistem kelarasan, dimana setiap laras membawahi beberapa nagari yang secara historis dan adat dianggap homogeni. Kelarasan Kamang meliputi 4 nagari yaitu: Nagari Kamang, Nagari Bukik, Nagari Suayan dan Nagari Sungai Balantiak.

Tuanku Nan Renceh memiliki nama kecil Abdullah. la adalah putra dari Incik Rahmah. Tuanku Nan Renceh lahir di Bansa, Nagari Bukik Kamang (sekarang masuk Nagari Kamang Mudik), Luhak Agam. Beliau diperkirakan lahir tahun 1762. Berdasar adat tradisi Minangkabau yang menganut azaz 
matrilineal, Tuanku Nan Renceh bersuku (klen atau marga) koto, sedangkan bako-nya (keluarga sang ayah) bersuku pisang.

Menurut laporan pihak Belanda berdasarkan keterangan dari berbagai sumber di tahun 1830-an, Tuanku Nan Renceh bertubuh tipis dan kecil perawakannya, tetapi memiliki emosi yang tinggi, matanya "berkaca dengan api yang tidak biasa".

Pengetahuan agama Abdullah (Tuanku Nan Renceh) awalnya diperoleh di daerahnya sendiri nagari Bukik, Kamang. Disini telah ada pusat-pusat belajar dasar agama Islam. Tuanku Nan Renceh belajar pada gurunya yang bergelar Tuanku Samiak di Bansa. Hal besar yang telah dilakukannnya adalah dengan membuat terobosan untuk belajar ke kampung lain. Tuanku Nan Renceh atau Abdullah belajar ke surau Tuanku Nan Tuo di Cangkiang, Koto Tuo Luhak Agam.

Tuanku Nan Tuo mengajarkan pembaharuan kepada muridnya. la menjelaskan bahwa masyarakat sudah mulai banyak meninggalkan ajaran Islam. Dalam masa pendidikannya, Tuanku Nan Renceh terkenal sangat taat dan pintar. Sekembalinya beliau dari berguru di Cangkiang, Tunku Nan Renceh mulai mengajar di kampungnya. Namanya mulai terkenal diseluruh luhak Agam. Tahun-tahun terakhir abad ke-18 Tuanku Nan Renceh sudah aktif berdakwah bersama sahabatnya, Fakih Saghir yang merupakan anak dari Tuanku Nan Tuo. Tuanku Nan Renceh dan Fakih Saghir berhimpun bersama dalam masjid Kota Hambalau di nagari Canduang Kota Lawas. Mereka telah berdakwah selama empat tahun lamanya.

Pada tahun 1802 tiga orang haji asal Minangkabau pulang dari Makkah, yakni Haji Miskin dari Pandai Sikek (Pandai Sikat) Luhak Agam, Haji Muhammad Arief dari Sumanik, Luhak Tanah Datar (dikenal dengan Haji Sumanik), dan Haji Abdur-rahman dari Piobang, Luhak Limopuluah Kota (dikenal dengan Haji Piobang). Hampir 10 tahun lamanya mereka mendalami ajaran Wahabi saat belajar di tanah suci Makkah. Saat Haji Miskin dan kawan-kawannya pulang dari Mekkah, Tuanku Nan Renceh waktu itu masih seorang ulama muda, namun beliau telah aktif berdakwah sejak tahun 1799 .

Sekembalinya Haji Miskin ke kampung halaman di Pandai Sikek, Haji Miskin berniat ingin melakukan perubahan. Perubahan yang diinginkan oleh Haji Miskin adlah menghentikan budaya lama yang bertentangan dengan ajaran Agama Islam. Tetapi karena perubahan yang dilakukan saat itu tidak memproleh dukungan, Haji Miskin kemudian diusir dari kampungnya sendiri. Bagi Abdullah, Tuanku Nan Renceh, kabar “diusirnya” Haji Miskin justru membuat penasaran. Seandainya ajaran yang dibawa Haji Miskin tak terlalu istimewa, tentulah perlawanan dari orang kampung sendiri tidak sehebat itu. 
Ternyata benar. Ketika Tuanku Nan Renceh bertemu dengan Haji Miskin di tempat pengungsiannya, Nagari Ampek Angkek, Tuanku Nan Renceh mendapat pelajaran tentang pemurnian gerakan Islam.

Berdasarkan permintaan Tuanku Nan Renceh, akhirnya Haji Miskin berangkat ke Bukit Kamang. Haji Miskin tinggal bersama Tuanku Nan Renceh di Surau Bansa (1805-1811). Haji Miskin dan Tuanku Nan Renceh mulai mengatur rencana pembaruan secara menyeluruh untuk menerapkan hukum Islam dalam melengkapi hukum adat Minangkabau.

Kita tidak tahu seberapa dalam pemahaman kelompok Paderi tentang ajaran Wahhabi, namun masyarakat Islam ideal yang dikembangkan oleh ajaran Muhammad 'Abdul al-Wahhab (1703-1792) inilah yang nampaknya mereka tiru. Ajaran Abdul al-Wahhab untuk reformasi masyarakat Islam berpusat pada hal ketauhidan, kehidupan muslim, serta tata cara mendekatkan diri pada Allah SWT. Pengajaran ini memberikan acuan agar sebagai seorang muslim harus hidup sesuai dengan aturan yang ditetapkan dalam Al Qur'an dan sunah dan membuat mereka menjadi muslim ideal. Hal itu sangat identik dengan misi kelompok Paderi yaitu membersihkan berbagai pengaruh adat yang berlawanan dengan ajaran agama.

Gerakan pemurnian Islam yang bersumber dari gerakan Wahhabi di kalangan masyarakat di Minangkabau membawa dampak pada keinginan masyarakat untuk beribadah ke tanah suci Mekkah. Kekayaan yang baru diperoleh masyarakat dari hasil kegiatan perdagangan ini telah memungkinkan semakin banyaknya masyarakat untuk melakukan ibadah haji. Masyarakat yang pulang dari ibadah haji menjadi peka terhadap perkembangan di Kota suci Mekkah.

Hal utama yang ditentang oleh kelompok Paderi adalah orang Islam yang membaurkan Islam dengan budaya khurafat, dan adat lama nagari yang bertentangan dengan ajaran Islam. Masyarakat yang menjalankan hal seperti itu biasanya dikuasai oleh datuk-penghulu, bangsawan, bahkan keturunan Pagaruyung. Perkelahian di pasar, pembakaran surau yang menjadi markas Paderi sering terjadi, bahkan serangan antar nagaripun sering tidak terelakkan.

Kaum Paderi umumnya juga membersihkan kelompok penyamun yang merampok konvoi-konvoi pedagang di jalur lintas perdagangan pantai barat dan pedalaman. Mereka juga menjalin hubungan dengan pedagang pantai barat dan timur Sumatera sehingga jaringannya makin luas dan kuat.

Kelompok adat yang tidak suka dengan gerakan Tuanku Nan Renceh menawan lima orang kemenakannya dan dibawa ke Bukik Batabuah. Selain itu ada juga seorang tuanku dari kelompok Paderi yaitu Tuanku Tarabi dirampas 
hartanya di Koto Baru. Hal ini membuat Tuanku Nan Renceh marah dan menyerang balas ke Koto Baru sehingga daerah ini dikuasai kelompok Paderi.

Gerakan permurnian Islam oleh kelompok Paderi tetap bertumpu pada ajaran Islam yang mengajarkan peningkatan pemahaman tentang hal-hal berikut.

1. Aqidah, berkaitan dengan kepercayaan kepada Allah, Nabi dan Rasul, Kitabullah, Malaikat, hari kiamat dan kadar baik dan kadar buruk. Kebiasaan lama yang bertentangan dengan hal itu adalah masih adanya kepercayaan pada tahayul, benda keramat dan tindakan-tindakan syirik yang masih ada di masyarakat.

2. Ibadah, nilai aqidah dilaksanakan dalam bentuk ibadah yang dijelaskan oleh rukun Islam yaitu; mengucapkan kalimat Syahadat, mendirikan Sholat, berpuasa pada bulan Ramadhan membayar zakat dan mengerjakan haji bagi yang mampu. Dari konsep ibadah ini Tuanku Nan Renceh melakukan pengawasan ketat melaksanakan shalat wajib lima waktu.

3. Mu'amalah, yakni hal yang berkaitan dengan aturan-utaran mengenai hubungan antara manusia dengan manusia. Tuanku Nan Renceh menegaskan untu memakai pakaian putih bagi laki-laki, mengenakan pakaian jubah panjang sampai mata kaki, rambut dicukur habis, memakai sorban putih, seuntai tasbih di sebelah kiri dan pedang di tangan kanan, serta membawa kitab Al Qur'an di dalam saku tas merah digantungkan di leher. Orang perempuan diminta memakai baju kurung yang sampai ke lutut, dan dianjurkan sampai ke mata kaki. Kepala ditutup dengan sehelai kerudung atau jilbab, yang terlihat hanya mata. Setiap waktu sholat disuruh ke masjid dan saat mandi diwajibkan memakai kain basahan. Tempat mandi harus terpisah antara laki-laki dan perempuan. Siapa yang melanggar peraturan ini akan di peringatkan, didenda dan dihukum mati.

4. Akhlak, berhubungan dengan tingkah laku manusia dalam hal mengerjakan perbuatan baik dan menjauhi perbuatan buruk. Tuanku Nan Renceh menetap-kan petugas khusus di tiap nagari yaitu Qadi dan Imam yang berhak memberi hukuman. Mereka adalah orang yang tegas dan keras terhadap orang melanggar.

Dalam (Kampen, 1850) digambarkan sebagai berikut.

"kelompok kaum Paderi menggunakan pakaian putih, mencukur rambut kepalanya, menggunakan sorban putih, rosario (tasbih) di satu tangan dan pedang di sisi lain, dan bagi para imam salinan Qur'an selalu dalam kantong, Rooden dikenakan leher. Wanita menggunakan rok, mereka lama dalam berganti pakaian dan menutupi kepala 
dengan kerudung. Arah di dalam pemba-haruan bermula di Kamang menjalar ke Lintau, Alahan Panjang, Bonjol, dan Rao”.

Ajaran Islam yang telah dianut berabad-abad di dalam masyarakat Minangkabau mulai diabaikan oleh pihak-pihak yang dianggap terpandang di bidang adat. Dalam kehidupan sehari-hari mereka lebih patuh kepada aturan adat. Ajaran Islam umumnya hanya dipatuhi oleh rakyat di kalangan bawah, ulama serta murid-muridnya. Mereka tidak berdaya melakukan perubahan karena tidak punya harta dan kekuasaan politik. Suara para ulama hanya didengar sebatas masjid dan surau. Dekadensi moral masyarakat Minangkabau pada masa itu sudah berada pada tahap mengkhawatirkan.

Melihat situasi keagamaan yang makin merosot, maka golongan ulama melancarkan gerakan kembali ke syariat Islam, dengan membasmi bid'ah dan khurafat. Mereka melakukannya dengan pendekatan persuasif melalui dakwah dan pengajian. Praktek pemurnian ajaran Islam telah diusahakan oleh Tuanku Nan Tuo dan para muridnya dengan jalan damai. Namun, kemudian muncullah orang-orang yang keras dan militan untuk menegakkan syariat Islam, mereka itulah kelompok Haji Miskin, Haji Sumanik dan Haji Piobang yang didukung oleh ulama militan seperti Tuanku Nan Renceh, Tuanku Pasaman, Tuanku Lintau dan yang lainnya. Akibatnya, muncullah perselisihan bahkan pertumpahan darah antara sesama orang Minangkabau. Keadaan masyarakat pada masa itu kita dapat lihat dari penjelasan Fakih Saghir berikut.

Semuhanya mengerjakan lalim aniaya, menyamun dan menyakar, melaka' dan melakus, maling dan mencuri, menyabung dan bejudi, minum tuak dan minum kilang, memakan sekalian yang haram, merabut dan merampas, tidak* berbezo halal dan haram, larangan dan pegangan, dan mau berjual orang; dan jikalau ibunya dan syaudaranya* sekalipun, dan banyaklah orang dagang dirampasnya dan dijualnya.

Christine Dobbin menggunakan istilah agama petani untuk masyarakat Minangkabau yang memeluk Islam tetapi tidak melaksanakan ajaran dengan sesungguhnya. Mereka memiliki beberapa tokoh kunci canayang/pawang (dukun), pawang diminta mengusir kekuatan gaib, menjaga keamanan (Dobbin, 1998). Berbagai kegiatan kelompok adat yang bertentangan dengan nilai-nilai pemurnian Islam mulai dipertontonkan untuk memancing keributan.

Di Bukit Batabuah ada pasar yang melakukan adu ayam secara terbuka, sebagai salah satu wujud penentangan kelompok adat di daerah ini terhadap ajaran pemurnian Islam. Tuanku Nan Tuo datang ke tempat adu ayam dengan tujuan untuk membujuk dan menutup arena adu ayam. Akan tetapi kelompok 
parewa (preman) membawa parang dan batu sehingga tidak bisa dihindari lagi terjadinya perkelahian hebat.Tuanku Nan Tuo berhasil melarikan diri, dan mempersiapkan kelompoknya untuk melakukan serangan balik ke Bukit Batabuah dan menghentikan adu ayam.

Tuanku Nan Renceh melihat usaha Tuanku Nan Tuo di daerah Biaro-Ampang Gadang dan Bukit Batabuah yang penuh ketenangan, kesabaran seperti itu akan sia-sia. Tuanku Nan Renceh mengobarkan semangat jihad yang keras dan langsung dengan aksi nyata.

Tahap awal Tuanku Nan Renceh berhasil menaklukkan daerah Dala (Salo), Magek, Kota Baru (Koto Baru) dan kampungnya sendiri Kamang Bukik. Muhammad Rajab menggambarkan situasi itu sebagai berikut.

"Tuanku Nan Renceh dengan beratus-ratus pengikutnya tidak sabar lagi melihat kemunafikan rakyat, terutama dalam daerah Luhak Agam di awal abad ke 18. Tuanku Nan Renceh melakukan serangan serentak ke daerah-daerah Tilatang, Padang Tarab, Canduang, dan Ujuang Guguak. Semua kampung mereka kalahkan melalui peperangan yang banyak memakan korban, dan bagi kampung yang mereka kalahkan diharuskan membayar upeti 400 ringgit. Setelah itu Tuanku Nan Renceh segera menggempur Agam Tuo secara keseluruhan, menyerang Matur dan semua kampung di sekitar Matur dengan mudah dapat dikuasai oleh pasukan Tuanku Nan Renceh. Oleh karena Matur tidak memberikan perlawanan, Matur tidak wajib membayar upeti, kecuali seluruh kampung yang telah dikuasai oleh pasukan Tuanku Nan Renceh diharuskan memelihara jenggot dan mencukur habis rambut di kepala. Di samping itu kepada seluruh penduduk tidak diboleh-kan memakan sirih, merokok, berjudi, menyabung ayam, minum tuak, dan siapa yang melangar larangan ini akan dihukum mati”.

Pada perkembangannya kelompok Paderi berhasil menertibkan nagari-nagari yang dikuasainya. Tuanku Nan Renceh menyerang nagari yang tidak meramaikan masjid dan surau di Tilatang. Dalam penyerbuan itu, beliau membakar surau-surau yang telah ditinggalkan masyarakat dan tetap mempertahankan surau dan masjid yang masih ramai diisi oleh penduduk dalam beribadah. Salah satunya surau yang tetap dipertahankan adalah Surau Tingga di Koto Laweh. 
Dalam buku Syafnir Aboe Nain Dt. Kando Marajo, Nurmatias (2009) dapat diketahui hal berikut.

Fasal ke sepuluh, kemudian dari pada itu dan kompeni yang pai pulang perang di Koto Baharu di tanah Agam juga dan tibalah kompeni ke sinen dan baparanglah orang Koto Baharu gelarnya Tuanku Nan Renceh. Dan banyaklah kompeni-kompeni mati perang di Koto Baharu, dan kompeni pun lari semuanya dan tinggallah satu meriam kompeni di Koto Baharu itu.

Kepemimpinan dan aksi Tuanku Nan Renceh berhasil melaksanakan pemurnian Islam dan memasukkannya ke dalam ruang lingkup pemerintahan nagari. Pelaksanaan ibadah shalat dalam kehidupan masyarakat dikontrol secara ketat. Dalam rangka penegakan hukum, Tuanku Nan Renceh sangat tegas dan berwibawa. Setiap orang yang melakukan pelanggaran terhadap ajaran Islam dan berbuat criminal akan dihukum sesuai syariat Islam.

Tuanku Nan Renceh menetapkan pelaksanaan hukum Islam di tiap nagari dengan menempatkan seseorang dengan jabatan qadi dan tuanku. Qadli/Qadi bertugas menjadi hakim dalam masalah agama Islam di nagarinya. Pengawas pelaksana pengamalan ajaran agama dalam kelompok adat atau suku ditugasi seorang Malim/Alim. Jabatan Tuanku diberikan pada imam di setiap nagari yang dikuasai Paderi. Orang yang menjalankan amanah ini lebih akrab dipanggil dengan panggilan Tuanku Imam.

Hamka menjelaskan perjuangan Tuanku Nan Renceh dan Tuanku Imam Bonjol "Dia mencampungkan diri ke dalam gerakan Paderi, setelah sampai seruan Tuanku Nan Renceh dari Kamang ke Bonjol. Dan Tuanku Nan Renceh menerima pula pelajaran itu daripada tiga Tuanku yang pulang dari Makkah, membawa pokok pelajaran Tauhid yang suci bersih, menurut pandangan Ibnu Taimiyah dan Muhammad bin Abdul Wahhab (Wahabi).

Tuanku Nan Renceh telah mampu memberikan pelajaran dengan semangat perjuangan di suraunya. Ada Masyarakat setuju dan gembira, namun sebaliknya ada yang tidak setuju dan mengejek gerakan itu serta dianggap sebagai usaha yang sia-sia. Kelompok para pedagang umumnya menerima dan mendukung usaha ini. Mereka berjanji saling membantu karena selama ini mereka sering menjadi korban karena di rampok oleh para penyamun.

Kuatnya gerakan Tuanku Nan Renceh dan kelompok Paderi mendorong Kaum Adat untuk meminta bantuan kepada Belanda. Pada 21 Februari 1821 mereka resmi menyerahkan wilayah darek kepada Kompeni Belanda. Perjanjian penyerahan wiayah darek itu ditandatangani di Padang. ini merupakan kompensasi kepada Belanda yang bersedia membantu kelompok 
adat dalam melawan Kaum Paderi. Dalam perundingan ini yang ikut "mengundang" adalah sisa keluarga Dinasti Pagaruyung di bawah pimpinan Sultan Muningsyah yang selamat dari pembunuhan oleh pasukan Paderi.

Sengitnya pertempuran yang dialami Belanda menghadapi pasukan Paderi dapat diketahui melalui tulisan seorang sejawan bangsa Belanda bernama Lauts (Amran, 1981). la mengungkapkan sebagai berikut:

"perang-perang pertama sesu-dah 1816, hanya
berlangsung dalam waktu singkat, tetapi peperangan di Sumatera Barat merupakan pertempuran sengit, kejam, gigih dan dalam waktu yang lama. Kalaupun tidak merupakan peperangan maha besar, namun dalam hal kesengitan, keberanian dan kegigihan sama sekali tidak kalah dengan peperangan atau pertempuran besar dimanapun.

Di awal tahun 1820-an Tuanku Nan Renceh sudah menjadi salah seorang komandan perang Kaum Paderi yang sanga kuat. Fakih Saghir menggambarkan aksi bengis pasukan Tuanku Nan Renceh ketika menyerang nagari Tilatang dengan penjelasan berikut.

"Maka sampailah habis nagari Tilatang dan banyaklah (orang) berpindah dalam nagari; dan sukar menghinggakan ribu laksa rampasan, dan orang terbunuh dan tertawan lalu pada terjual, dan (wanita) dijadikannya gundi'nya”.

Pada periode awal Paderi yang berlangsung dari tahun 1804 -1806, para pengikut Paderi diberi pembekalan awal berupa pendidikan agama yang lebih dalam. Tuanku Nan Renceh mendidik calon Panglima Paderi. Tuanku Imam Bonjol, Tuanku Rao dan sejumlah rombongan datang di Kamang. Rombongan itu diperkirakan sekitar 500 orang yang dibawa oleh Datuk Bandaro Ganggo dari Lubuk Sikaping dan daerah di Sumatera Utara. Dalam waktu yang bersamaan Haji Piobang dan Haji Sumanik juga ikut memberi pendidikan dan melatih tentang ilmu kemiliteran. Pada tahun 1803-1807 Haji Piobang telah mempropaganda bahwa orang Islam dijajah para kafir sehingga harus dilawan.

Tuanku Nan Renceh disebut-sebut menjabat sebagai kepala Negara Darul Islam Minangkabau. Tuanku Nan Renceh juga membentuk markas besar dan aktif memberikan pendidikan agama Islam serta mendirikan benteng di Kamang. Kekuatan Paderi dilengkapi dengan angkatan bersenjata dengan keunggulan pasukan kavalleri Islam. Lebih kurang 32.000 personil tentara dengan keunggulan teknik pertempuran berkuda. Mereka dibina oleh Haji 
Piobang dan Haji Sumanik. Sedangkan Haji Miskin dengan kemampuan bertempur di Padang Pasir (hermet). Mereka telah terkenal dengan pertarungan hidup mati di padang pasir Timur Tengah. Para haji tersebut sudah terlatih dengan pertempuran bersama tentara Turki saat menghadapi Napoleon di Mesir. Dalam diskusi bersama masyarakat Kamang, di daerah Aia Tabik kita bisa menemukan sebuah makam dengan batu nisan bertulis nama Syech Istambul yaitu seorang pelatih pasukan tentara Paderi dari Turki.

Di Bansa, Tuanku Nan Renceh mendirikan sebuah dewan khusus, dimana para pedagang yang pernah dirampok bisa menyampaikan laporan. Tuanku Nan Renceh juga menyusun daftar daerah-daerah bandit atau kampung yang dihuni banyak penyamun serta daftar kampung yang mempertahankan tradisi bertentangan dengan ajaran Islam. Ada juga daftar daerah yang banyak terdapat penjahat dan pernah memulai serangkaian serangan terhadap mereka (kelompok Paderi). Di desa-desa atau nagari yang dikuasai Kelompok Paderi semua sabung ayam, judi dan penggunaan tembakau, opium, sirih-pinang dan minuman keras dihapuskan.

Kelompok Paderi melarang aksi sabung ayam, berjudi, mengisap candu, meminum tuak, merampok, membunuh, dan sebaliknya menguatkan sembahyang 5 waktu, puasa, berzakat, fitrah, shalat Jum'at di surau setidaknya 40 orang tiap nagari. Haji Miskin menambah dengan aturan melarang merokok, larangan makan sirih.

Diantara hukum yang ditetapkan di masa itu antara lain sebagai berikut.

1. Laki-laki mencukur janggut didenda 2 suku.

2. Mengasah gigi didenda 1 ekor kerbau.

3. Perempuan tidak menutup muka didenda 3 suku.

4. Memukul anak didenda 2 suku.

5. Menjual atau memakai tembakau didenda 5 suku.

6. Meninggalkan shalat didenda 5 real, kalau mengulanginya maka bisa di hukum mati (1 suku = 0,5 Gulden).

Tuanku Nan Renceh membentuk kelompok sendiri yang terkenal dengan sebutan "Harimau Nan Salapan” yang militan. Harimau Nan Salapan terdiri dari:

1. Tuanku di Kubu Sanang.

2. Tuanku di Ladang Lawas.

3. Tuanku di Padang Luar.

4. Tuanku di Galuang.

5. Tuanku di Kota Hambalau.

6. Tuanku di Lubuk Aur.

7. Tuanku Nan Renceh (pemipin-panglima perang). 


\section{Tuanku Haji Miskin.}

Itulah tujuh orang yang berbai'ah (berjanji sehidup semati) dengan “Harimau Nan Salapan” (Kratz \& Amir, 2002).

Harimau Nan Salapan diberi tugas memberitahu hal ini ke seluruh nagari mereka dan meminta untuk melaksanakan aturan ini. Penghulu yang tidak sesuai dengan aturan ini menentang sehingga muncullah kerusuhan di berbagai daerah. Kaum agama juga menentang masalah pembagian harta pusaka di Minangkabau yang tidak sesuai dengan aturan agama.

Tuanku Nan Renceh dan pengikutnya yang militan kemudian menjadi lebih terkenal. Usai shalat subuh di surau-surau, Tuanku Nan Renceh menurunkan Laskar Paderi keliling kampung. Mereka bertugas memeriksa batu tapakan yang sudah disediakan di setiap pintu masuk rumah penduduk. Apabila batu itu basah, diketahuilah bahwa penghuni rumah sudah mengambil air wudhu dan melaksakan shalat Shubuh. Tapi bila tidak, semua penghuni rumah akan langsung diinterogasi. Andai belum shalat karena tertidur, maka diperintahkan untuk segera menunaikan shalat. Bila tiga kali diketahui orang tersebut tidak juga menunaikan shalat, maka penghuni rumah harus bertaubat kepada Allah SWT. Akan tetapi bila kemudian terbukti meninggalkan shalat kembali, maka penghuni rumah harus meninggalkan nagari.

Tuanku Nan Renceh mengatur pemilihan wali nagari. Untuk menjadi wali nagari (kepala pemerintahan nagari) harus mampu menjadi imam shalat berjamaah. Hukum Islam yang ditegakkan kaum Paderi dalam masa kepemimpinan Nan Renceh sangat tegas dan berwibawa.

Salah seorang kerabat Tuanku Nan Renceh sendiri ternyata diam-diam menggunakan opium dan tembakau, ia diadili dan dihukum mati. Bibi Tuanku Nan Renceh yang tetap berpakaian hitam, minum tuak, dan berlawanan dengan hukum Islam mendapat hukuman mati. Eksekusi dilakukan oleh Haji Idris Bin Haji Hassan. Hal ini sesuai dengan berita dalam tulisan Kampen (1850) mengemukankan hal ini dalam kutipan berikut.

"Toewankoe Rintji Nan, salah satu pendukung paling bersemangat dalam reformasi Islam, ia membunuh dengan tangannya sendiri salah seorang saudaranya, yang menggunakan opium dan tembakau secara rahasia, dan meninggalkan tubuhnya ke burung pemangsa”.

Laporan Belanda tahun 1833 menjelaskan "ketertiban yang terdapat di berbagai desa-kampung Paderi memang mencolok. Di pasar tidak lagi terdengar pertengkaran, masing-masing menanyakan harga dan membayarnya kalau sesuai dengan keinginan mereka tanpa tawar menawar". 
Setelah pertempuran sengit di bulan Maret 1822 Belanda mengalahkan Tuanku Lintau, menguasai Tanah Datar. Tuanku Lintau melarikan diri ke perbukitan. Sedangkan Belanda terus menguasai Pagaruyung, Saruaso, Tabek Patah, dan Salimpaung. Juni 1822 Belanda berlanjut menguasai daerah Agam seperti Candung, Koto Tuo, Sungai Puar, Banuhampu. Raff begitu bernafsu ingin menaklukkan Tuanku Nan Renceh di Kamang. Namun strategi pertahanan Paderi di Kapau mampu menahan serangan dan memukul mundur AT. Raff. Pada tanggal 15 Agustus 1822 serangan diulangi lagi oleh Belanda untuk menguasai Kapau dan Tilatang, namun serangan itupun masih mampu ditahan oleh Kelompok Paderi. September 1822 Belanda diusir dari Sungai Puar, Guguk Sigadang.

Februari 1823 AT. Raff kembali meminta bantuan ke Batavia. Dari Batavia dikirim persenjataan dan tentara Belanda untuk membantu usaha penguasaan atas Minangkabau. Kedatangan bantuan ini membuat Raff berani menyerang Bukit Marapalam (daerah antara Tanah Datar dan Lima Puluh Kota). Namun 17 April 1823 ternyata Belanda mampu dikalahkan. Melihat keadaan pasukan Belanda yang makin tersedak, untuk itu pada tangga $15 \mathrm{Mei}$ 1825 Belanda dan Paderi menyepakati perjanjian damai. Diantara isi perjanjian itu adalah sebagai berikut.

1. Belanda mengakui kekuasaan Paderi di Batusangkar, Saruaso, Padang Gamuk, Agam, Bukittinggi, serta menjamin pelaksanaan agama.

2. Secara bertahap Belanda melarang adu ayam.

Keuntungan yang diperoleh oleh Belanda antara lain; kekuasaan Belanda di beberapa daerah yang telah dikuasai itu jadinya diakui oleh Paderi (seperti di daerah Padang). Belanda bisa membuat pajak ekspor-impor, pajak kepala, pajak candu di daerah kekuasaannya. Perjanjian ini dianggap sebagai sebuah kemenangan oleh kelompk Paderi, bahkan Tuanku Nan Renceh pernah mengirim surat kepada De Stuers yang isinya menegaskan bahwa pihak yang kalah harus membayar sejumlah uang pada pihak yang menang yang disebut dengan Jazyah. Hal ini dibalas dengan surat pribadi oleh De Stuers bahwa hal itu tidak mungkin dilakukannnya ataupun oleh pemerintahan Belanda (VOC). Namun ternyata sebaliknya Batavia menyetujui dan membayarkan 100 gulden kepada masing-masing tuanku sebagai uang damai. Keadaan damai tersebut dapat berlangsung beberapa waktu. Kekuatan, keuangan dan keadaan persenjataan menguntungkan Belanda (VOC) yang sibuk menghadapi Pangeran Diponegoro di Jawa.

29 Oktober 1825 kolonel de Stuers mencari jalan damai untuk menyelamatkan kekuasan Belanda di Minangkabau. Sementara saat itu di Jawa sedang bergolak perlawanan Pangeran Diponegoro. Dengan bantuan orang arab Said Salim Al-Jafrid (orang Arab dihormati kaum Paderi, dianggap 
keturunan nabi) melakukan perundingan dengan para tuanku penggerak Paderi yang dipimpin Tuanku Keramat dan De Stuers. Isi kesepakatannya tersebut antara lain sebagai berikut.

1. Kedua belah pihak tidak akan saling menyerang.

2. Kekuasaan Tuanku - Tuanku di Lintau, Lima Puluh Kota dan Kamang Agam diakui.

3. Mengusahakan bersama perlindungan atas lancarnya perdagangan.

4. Belanda tidak akan mencampuri urusan agama penduduk.

Perjanjian itu berlangsung di Padang pada tanggal 15 Nopember 1825. Pimpinan Kaaum Paderi yang hadir dalam perjanjian tersebut diantaranya adalah Tuanku Nan Renceh dan Tuanku Pasaman (Tuanku Lintau). Jadi dalam perjanjian itu disepakati kedua pihak tidak akan saling serang-menyerang lagi. Dalam rombongan itu juga terdapat Tuanku Nan Saleh dari Talawi, Utusan Tuanku Guguak dari Lima Puluh Kota, dan delapan orang tuanku lainnya, juga ikut dalam rombongan 54 orang murid yang memakai pakaian putih. Rombongan para Tuanku ini tinggal di Padang selama 20 hari. Dalam perundingan itu pimpinan Paderi meminta agar Belanda meninggalkan pedalaman dan hanya membatasi diri di pantai. Belanda juga diharapkan agar bersedia membantu untuk menyebarkan keyakinan Paderi di Tanah Datar, serta secara bertahap melarang pengisapan candu dan pertandingan adu ayam jago di Tanah Datar. Namun demikian, perjanjian ini kemudian hanya menghasil kesepakatan yang bersifat umum, yaitu: Belanda mengakui kekuasaan keempat pimpinan Paderi dalam wilayah masing-masing dan hak mereka untuk memberlakukan sistem agama mereka. Sebaliknya Paderi mengakui kekuasaan Belanda. Kedua belah pihak berjanji akan saling melindungi pedagang-pedagangnya.

Tahun 1829 Pemerintahan Belanda di Sumatera Barat dipimpin oleh residen baru Mac Gillavry. la membuat laporan yang menceritakan tentang kekacauan di Minangkabau yang disebabkan oleh kelompok Paderi. Juni 1830 kelompok Paderi dari Bukit Kamang berhasil memutuskan komunikasi antara benteng Belanda di Tanjung Alam dan Bukittinggi. Gillvary kemudian bereaksi membalas dengan menyerang Koto Tuo, Ampang Gadang, Biaro, Batang Gadis, Tanjung Alam dan Batusangkar. Inilah kemenangan gemilang pertama pihak Belanda.

Kamang yang menjadi pertahanan Tuanku Nan Renceh saat diserang Belanda, kampung Bansa jatuh, Agam dikuasai Belanda 30 Juli 1830. Setelah tekanan Belanda mereda di Kamang, Magek, Koto Baru, dan Salo penduduk bergerak menutup jalan-jalan didaerahnya. Tuanku Alam yang sebelumnya memihak Belanda, balik bergabung dengan kaum Paderi Kamang. Tetapi 
kemudian Tuanku Alam dibawa ke Biaro, Mayor de Quey melaksanakan hukuman dengan pemenggalan dan dipancangkan dengan sebuah galah di pintu benteng.

Gubernur Jenderal Van Den Bosch menunjuk C.J Riesz untuk memegang kekuasaan sipil dan militer di Sumatera Tengah. Dengan tujuan utama menumpas Paderi di Bonjol dan Agam. Bala bantuan Belanda yang dikirim dari Batavia untuk mengatasi perang Paderi membuat perang makin berkobar di Minangkabau. Pasukan Belanda yang ada menjadi kewalahan dan nyaris kalah, karena sejak 1832 telah bersatunya pasukan Paderi dan pasukan adat untuk menentang Belanda. Mereka melakukan pertemuan rahasia di lereng Gunung Tandikat dengan hasil akan bersatu padu menentang Belanda dan menghapus perselisihan dan pertentangan selama ini.

Perjuangan Tuanku Nan Renceh mulai terdesak sejak kedatangan pasukan Belanda di Magek dan Tilatang. Belanda diterima dengan baik di daerah itu, bahkan meriam Belanda (yang didapat saat perang di Koto Baru) dikembalikan pada penjajah (Belanda). Belanda kemudian membuat benteng pertahanan di Tilatang sehingga Kamang makin terdesak.

4 Maret 1831 Gillavry digantikan Letnan Kolonel Elout, dia diminta oleh Van Den Bosch untuk bersiap menyerang Paderi secara besar-besaran. Elout dibantu dengan tambahan senjata dan tentara. Tahun 1831 dikirim 1.500 tentara tambahan untuk perisiapan menyerang Kaum Paderi. Tahap awalnya Elout mulai menyerbu daerah Lintau, VII Koto, Manggung, dan Naras. Bulan Juni 1831 terus ke Batipuh dan Benteng Marapalam. Di daerah pantai serangan Belanda berlanjut ke Katiagan dan Muaro Batang Masang. Daerah pantai ini adalah salah satu daerah tempat mengirim mesiu, meriam, senjata untuk kelompok Paderi.

Bulan November 1831 Tiku dan Air Bangis diserang Balanda. Hingga akhir tahun 1831 datang lagi tambahan pasukan Belanda sebanyak 300 tentara. 1832 daerah Bukit Kamang yang merupakan pusat kekuatan Tuanku Nan Renceh diserang Belanda yang berlanjut ke Nagari Pauh. seluruh daerah Agam dikuasai.

Tuanku Nan Renceh pernah pula berkirim surat kepada Tuanku Imam Bonjol. Isi surat tersebut berbunyi sebagai berikut.

"seboleh-boleh permintaan saya lawan juga kompeni. Saya menolong kepada Tuanku Lintau apa kekurangan saya menolong dan sekarang ini saya kirim satu meriam dengan dua puluh sinapang, obat empat puluh puun dan anak peluru 400 dan itulah pakirim Tuanku Nan Renceh kepada Tuanku Imam Bonjol. 
Momen penting dalam sejarah kepemimpinan Paderi terjadi pada 11 Januari 1833. Saat itu Kepemimpinan Paderi diserahkan kepada Tuanku Imam Bonjol. Tuanku Imam Bonjol didaulat sebagai pengganti Tuanku Nan Renceh. Serangan besar Belanda datang ke Kamang pada tanggal 9 dan 10 Juli 1833. Kamang diserang dari 4 penjuru daerah berikut.

1. Dari jurusan Suliki melalui Bukit Batu Bajak, Melewati daerah batas antara Agam dan Limapuluh Kota, dipimpin oleh Mayor De Quay.

2. Dari jurusan Bukittinggi melalui Guguak Bulek, Gadut, Tilatang, dibawah pimpinan Van Der Taak.

3. Dari jurusan Bukittinggi melalui Tanjung Alam, Kapau, Bukik Kuliriak, Magek, Pintu Koto, dibawah pimpinan mayor Du bus.

4. Dari jurusan Baso melaui Salo, dipimpin oleh Overste Elout dan kapten Riezs.

Elout dan reisz dipukul mundur. Namun tanggal 10 juli, dengan turunnya pasukan Belanda dari Suliki membuat pasukan Paderi terkepung dan kalah. Pasukan Belanda terlalu kuat. Pada bulan Juli semua desa Kamang diambil alih dan diduduki oleh Belanda. Hal ini dipengaruhi oleh penghianatan Tuanku Limbur dari Suliki.

Tuanku Imam Bonjol sebagai pemimpin generasi kedua Gerakan Paderi menerapkan pola pembaruan Islam yang dipelopori Tuanku Nan Renceh dan Haji Miskin. Gagasan penanaman imam khatib dan qadhi di setiap nagari tetap dilanjutkan oleh Tuanku Mudo (Tuanku Imam Bonjol). Tuanku Imam Bonjol yang dinobatkan menjadi Tuanku Imam, kemudian pergi ke Bansa menemui Tuanku Nan Renceh dan kembali dengan seratus orang Kamang menghadiri perjamuan penobatan Tuanku Mudo menjadi Tuanku Imam untuk daerah Pasaman. Satu persatu kampung sekitar Bonjol dikuasai oleh hulubalang Bonjol dan Hulubalang Tuanku Nan Renceh.

11 Januari 1833 Minangkabau bersatu melawan Belanda di bawah komando Tuanku Imam Bonjol. Beliau mengikuti cara-cara Haji Miskin dan Tuanku Nan Renceh dan memperkuat bentengnya di Bonjol sebagai basis utara kelompok Paderi.

Vigelius (1851) dan Francis (1860) mengatakan bahwa Tuanku Nan Renceh wafat tahun 1832 di 'Medjang', sebuah daerah dalam wilayah Bukik-Kamang, Luhak Agam. Menurut analisis penulis, yang dimaksud adalah Mejan itu ada di Jorong Bansa, Kamang Mudiak sekarang, karena daerah dengan nama Mejan ini sampai sekarang masih ada dan di sana memang terdapat bekas-bekas pondasi bangunan, bekas jalan setapak, lesung dan batu besar seperti nisan atau lebih mirip menhir. 
Menurut Syafnir Aboe Nain Dt. Kando Marajo, Nurmatias (2009), Tuanku Nan Renceh wafat karena sakit. Dalam naskah ini diceritakan hal berikut,

\section{"Kemudian daripada itu maka tersebut pula perkataan (berita) Tuanku Nan Renceh dapat sakit. Dengan takdir Allah Taala tidak berapa lamanya dalam sakit itu dan berpulanglah (ia) ke rahmatullah adanya"}

Pada tahun wafatnya Tuanku Nan Renceh, pusat Gerakan Paderi sudah pindah ke Bonjol, dengan pemimpin utamanya Tuanku Imam Bonjol, salah seorang panglima Paderi yang 'dibesarkan' oleh Tuanku Nan Renceh sendiri.

Cerita tentang meninggalnya sosok penting dari kelompok Paderi yaitu Tuanku Nan Renceh memiliki beberapa versi. Hal itu akibat tidak diketahuinya berita tentang kematian beliau secara pasti dan tertulis. Beberapa versi yang berkembang dalam masyarakat antara lain:

1. Tuanku Nan Renceh meninggal dalam masa perang Paderi dan dibawa ke kampung Bansa untuk dikebumikan di kampung Pisang, Jorong Bansa.

2. Tuanku Nan Renceh meninggal karena diserang musuh beliau. Pada masa hidupnya Tuanku Nan Renceh tidak dapat didekati dan diserang oleh siapa pun dari kalangan musuh beliau. Untuk itu musuh Tuanku Nan Rencah telah bersepakat mencari jalan lain dan mendatangi beliau beramai-ramai. Tiap orang memegang sebatang galah panjang dan diujungnya diselipkan pisau. Mereka mengelilingi Tuanku dan dengan galah panjang tersebut menjatuhkan Tuanku Nan Rencah. Setelah beliau terjatuh mereka beramai-ramai menoreh kulit beliau dengan pisau cukur (amat tajam) hingga beliau meninggal dunia.

3. Tuanku Nan Renceh meninggal karena ditinggam oleh musuh beliau di surau Mejan-Bansa dan dimakamkan di tanah bako beliau Dt. Mangkudun suku Pisang.

4. Sebuah kisah tentang meninggalnya Tuanku Nan Renceh diawali dengan sekembalinya beliau dari peperangan membantu Tuanku Imam Bonjol di Kumpulan, Bonjol. Beliau kedatangan seorang tamu yang tak di kenal. Tamu tesebut membawa Al-Qur'an dan tongkat. Diperkirakan tamu ini adalah utusan Belanda yang disuruh untuk menemui Tuanku Nan Renceh. Tamu inilah yang diperkirakan menyerang Tuanku dengan kebatinan untuk membunuh beliau. Setelah pertemuan itu ternyata di daerah Baso, pasukan Belanda dan anak buahnya membuat patung yang diperkirakan mirip dengan Tuanku Nan Renceh. Patung ini disandarkan di kayu Miza. Dengan ilmu kebatinan dan jampi-jampi ditembaki. Saat itu Tuanku Nan Renceh yang sedang mengembala itik di dekat surau Mejan tersungkur dan meninggal. 
5. Menurut beberapa narasumber yang penulis temui ada yang menyatakan Tuanku Nan Renceh meninggal karena sakit, bukan karena berperang dengan Belanda.

Berbagai versi yang ada tentang meninggalnya Tuanku Nan Renceh tak menyurutkan arti penting beliau. Satu hal yang pasti bahwa semangat juang dan nilai-nilai positif lainnya telah diajarkan oleh Nyiak Enceh (sebutan dari masyarakat setempat bagi Tuanku Nan Renceh).

Meski Tuanku Nan Renceh telah meninggal, namun ternyata pada Januari 1835 ada lagi gejolak di Kamang yang juga melibatkan orang kelompok agama. Pasukan Belanda kembali dikirim masuk ke Kamang. Pergolakan Islam berikutnya muncul lagi di Kamang pada tahun 1908.

Setelah membaca berbagai sumber tertulis yang ada tentang perjuangan Tuanku Nan Renceh dan Gerakan Paderi ada tulisan yang memunculkan penilaian negatif terhadap tokoh Tuanku Nan Renceh. Tulisan itu mengangkat topik bahasan tentang tindakan Tuanku Nan Renceh bagi orang-orang yang melanggar aturan di nagari-nagari Kaum Paderi. Mereka dihukum, dan bila melanggar lagi maka akan diberi hukuman yang keras. Aturan agama dan hukuman yang diberikan pada kelompok adat itu terkesan sangar dan kejam sehingga atas dasar itulah banyak orang yang menilai bahwa Kelompok Paderi dan Tuanku Nan Renceh adalah sebuah gerakan Islam radikal yang keras dan berbahaya. Pemahaman ini berlanjut sampai sekarang, bahkan latar belakang sejarah kajian tentang kelompok Islam radikal, dimasa kinipun dikait-kaitkan dengan sejarah Tuanku Nan Renceh.

Bila diamati ternyata tulisan dan sumber-sumber sejarah terdahulu yang menyudutkan tersebut muncul dari lawan-lawan politik Kelompok Paderi pada zamannya. Tulisan ini adalah karya penulis-penulis Belanda, tokoh-tokoh pro Belanda yang menentang kelompok Paderi, dan kelompok agama yang berbeda pemahaman terhadap penerapan aturan Islam. Apakah tidak mungkin pernyataan-pernyataan dari lawan politik semacam itu adalah sebuah usaha pembunuhan karakter yang berkeinginan memunculkan stigma negatif bagi kaum Paderi dan Tuanku Nan Renceh? Kalau dibahas dalam konteks kekinian adalah munculnya hoax (berita bohong) yang didasari atas dasar kebencian dan pertentangan.

Ketika dilihat dari kajian agama, maka rasanya tidak mungkin adanya kelompok yang mengusung misi pemurnian ajaran Islam namun melakukannya dengan kekejaman yang diluar peri kemanusiaan dan diluar aturan Islam. Penerapan syariat Islam dengan dasar Al Qur'an dan Hadits yang digelorakan oleh Kelompok Paderi tentu tidak akan merusak sendi dasar gerakan mereka sendiri. Dasar pemberian hukuman dalam aturan hukum Islam bukan hal yang 
diberikan begitu saja. Ada berbagai aturan dan jalur yang akan ditempuh sebelum sampai pada satu keputusan, apalagi sampai pada adanya keputusan hukuman mati.

Untuk memposisikan Tuanku Nan Renceh dan Gerakan Paderi sebagai kelompok radikal, kasar, keras dan kejam sudah perlu direkonstruksi ulang agar ketokohan beliau dengan gerakan pemurnian Islam tidak terkesan sebagai cikal bakal Islam radikal dan teroris Indonesia. Zalim rasanya bila kita tetap mempertahankan nama beliau dalam posisi pencetus radikalisme Islam. Letakkan sumber bacaan yang menyudutkan beliau sebagai bahan dan referensi dengan memahami dasar penulisan itu dilakukan atau dalam istilah sejarah yaitu dengan memahami jiwa zaman (zeitgeist) dan jiwa si penulis.

Kita harus memahami gerakan pemurnian Islam yang beliau gelorakan sehingga bisa dilihat nilai kelebihannya. Bagaimana Kelompok Paderi mendudukan kembali aqidah, ibadah, akhlak, muamalat kembali ke dasar Islam bagi pemeluk Islam sebagai sebuah keunggulan. Pahami bagaimana beliau mampu membentuk masyarakat yang aman, pedagang dapat berdagang dengan tenang, kehidupan berjalan baik sebagai hal positif gerakan ini. Tuanku Nan Renceh serta gerakan Paderi telah menujukkan jasa besar dalam hal memunculkan rasa nasionalisme, cinta tanah air, anti penjajahan dengan bukti melawan penjajah Belanda dengan sekuat tenaga dan jiwa seperti inilah yang seharusnya kita warisi sampai sekarang. Sadarlah kita bahwa Islam adalah pembuat fondasi wawasan kebangsaan Indonesia.

$\begin{array}{ll}\text { Nama } & : \text { Tuanku Nan Renceh } \\ \text { Nama kecil } & : \text { Abdullah } \\ \text { Tempat/ Tgl Lahir } & : \text { Bansa, Nagari Bukik, Kamang/ } \\ & \text { Diperkirakan tahun 1762 M. } \\ \text { Meninggal Dunia } & : \text { Bansa, Nagari Bukik, Kamang/ } \\ & \text { Diperkirakan tahun } 1832 \mathrm{M} . \\ \text { Ayah } & : \text { Suku Pisang Bansa } \\ \text { Ibu } & : \text { Incik Rahmah / Aji Rahmah suku } \\ & \text { koto } \\ \text { Pendidikan } & \text { Pendidikan Formal, tidak ada. } \\ & \text { Pendidikan Informal. Pendidikan } \\ & \text { awal di peroleh dari keluarga di } \\ & \text { Kamang. }\end{array}$

Pendidikan Non Formal

1. Pendidikan non formal (agama Islam) di masa kecil Tuanku Nan 
Renceh adalah belajar mengaji dan silat di surau dengan gurunya bergelar Tuanku Samiak di Bansa.

2.Pendidikan non formal (agama Islam) dimasa remaja Tuanku Nan Renceh belajar ke surau Tuanku Nan Tuo di Cangkiang, Luhak Agam.

3.Sejak tahun 1799 Tuanku Nan Renceh sudah aktif berdakwah bersama sahabatnya, Fakih Saghir yang merupakan anak dari Tuanku Nan Tuo.

4.Pendidikan non formal (agama Islam) Tuanku Nan Renceh ditambah dengan belajar kepada Haji Miskin, berangkat ke Bukit Kamang tahun 1805.

Tabel 1: Biodata Singkat Tuanku Nan Renceh

Tahun (abad)

Abad XVIII

1802

1804

\section{Peristiwa}

: Kopi menjadi primadona ekspor yang banyak terdapat di darek. pertanian dan perdagangan makin maju. Namun diganggu oleh munculnya para

: penyamun-perampok

Tiga orang haji asal Minangkabau pulang dari Makkah, yakni Haji Miskin dari Pandai Sikek (Pandai Sikat) Luhak Agam, Haji Muhammad Arief dari Sumanik, Luhak Tanah Datar (dikenal dengan Haji Sumanik) dan Haji Abdurrahman dari Piobang, Luhak

: Limopuluah Koto (dikenal dengan Haji Piobang).

Di Kamang dikembangkan pendidikan bagi pengikut Paderi. 
$1805-1811$

1816

1820-an

21 Februari 1821

Februari 1823

17 April 1823

15 Mei 1825

15 Nopember 1825

Juni 1830

1831

Juni 1831

November 1831

1832

1832
: Haji Miskin berangkat ke Bukit Kamang dan menjadi guru agama di sana.

: Pasukan Paderi dan pasukan Belanda untuk pertama kalinya berperang.

: Tuanku Nan Renceh sudah menjadi salah seorang komandan perang Kaum Paderi yang kuat.

: Kelompok adat secara resmi menyerahkan wilayah darek kepada Kompeni melalui sebuah perjanjian di Padang.

: AT. Raff meminta bantuan ke Batavia. Dari Batavia diterima kiriman persenjataan dan tentara Belanda untuk membantu usaha penguasaan Minangkabau.

: Belanda mampu dikalahkan.

: Belanda dan Paderi menyepakati perjanjian damai.

: Kolonel de Stuers mencari jalan damai, untuk menyelamatkan kekuasan Belanda di Minangkabau. Sementara saat itu di Jawa sedang bergolak perlawanan Pangeran Diponegoro.

: Kelompok Paderi dari Bukit Kamang berhasil memutuskan komunikasi antara benteng Belanda di Tanjung Alam dan Bukittinggi.

: Letnan Kolonel Elout diminta oleh Van Den Bosch bersiap menyerang Paderi secara besar-besaran. Elout dibantu dengan tambahan senjata dan tentara. Tahun 1831 dikirimlah 1.500 tentara tambahan untuk perisiapan menyerang Paderi.

: Belanda menyerang Batipuh dan Benteng Marapalam.

: Tiku, Air Bangis diserang Balanda.

: Daerah Bukit Kamang, yang merupakan pusat kekuatan Tuanku Nan Renceh diserang Belanda yang berlanjut ke Nagari Pauh. Seluruh daerah Agam dikuasai.

: Diperkirakan di tahun ini Tuanku Nan Renceh Meninggal dunia. 


$\begin{array}{ll}\text { September } 1832 & : \begin{array}{l}\text { Belanda memasuki daerah Bonjol. } \\ 11 \text { Januari } 1833\end{array} \\ & \begin{array}{l}\text { Kepimpinan Paderi diserahkan pada } \\ \text { Tuanku Imam Bonjol. }\end{array} \\ 9 \text { Juli } 1833 & : \begin{array}{l}\text { Serangan terbesar dilakukan Belanda ke } \\ \text { Kamang melalui empat jurusan. }\end{array}\end{array}$

Tabel 2: Peristiwa Penting Seputar Paderi

\section{Simpulan}

Setelah membaca dan mempelajari tentang kemunculan kelompok Paderi di Kamang dan sejarah hidup Tuanku Nan Renceh, kita bisa mengambil beberapa kesimpulan bahwa berikut.

1. Tuanku Nan Renceh adalah salah satu dari orang Kamang-Bansa yang menjadi orang penting di zamannya, kita sebagai generasi muda harus merasa bangga dan termotivasi untuk bisa mempelajari, memahami tentang keberadaan Tuanku Nan Renceh.

2. Dalam hal urusan agama kita haruslah mematuhi dan mengikuti ajaran Islam dengan sebaik-baiknya, menjalankan rukun Islam dan memantapkan rukun Iman. Sebagai orang Minangkabau, kita juga dituntut untuk mempelajari adat istiadat Minangkabau sehingga nilai dan norma adat itu tidak makin pudar untuk menciptakan masyarakat yang beradab (agama) dan beradat.

3. Tempatkanlah Tuanku Nan Renceh sebagai tokoh yang berjasa dalam pemurnian Islam, jangan munculkan lagi stigma negatif dan Islam radikal pada sosok Tuanku Nan Renceh.

\section{Daftar Rujukan}

Ahmad Dt Batuah, A. D. M. (1957). Tambo Minangkabau. Jakarta: Dinas Penerbitan Balai Pustaka.

Amran, R. (1981). Sumatera Barat Hingga Plakat Panjang. Jakarta: Sinar Harapan.

Bachtiar Chamsyah, Ismael Hassan, D. (2009). Gerakan Paderi Pahlawan dan Dendam Sejarah. , Suara Muham-madiyah Yogyakarta Kerjasama Dengan Pemerintah Kab. Pasaman, Sumatera Barat.

Dobbin, C. (1998). Manifestationd De L'islam, Islamic Fervour as a Manifestation of Regional Personality in Colonial Indonesia: The Kamang Area, West Sumatra, 1803-1908. Paris: Archipel.

Dobbin, C. (2008). Gejolak Ekonomi, Kebangkitan Islam dan Gerakan Paderi Minangkabau 1784-1847. Jakarta: Komunitas Bambu.

Francis, E. (1860). Herinneringen uit den levensloop van een'Indisch'ambtenaar van 1815 tot 1851, Vol. 3. Batavia: HM van Dorp, 3, 73. 
Hadler, J., Berlian, S., \& Abdullah, T. (2010). Sengketa Tiada Putus: Matriarkat, Reformisme Agama, dan Kolonialisme di Minangkabau. Freedom Institute.

Hamka. (1963). Dari Pembendaharaan Lam. Jakarta: Pustaka Panjimas.

Kampen, P. N. van. (1850). De geschiedenis van Sumatra, Vierde Artikel bron: De Gids. Amsterdam.

Kratz, U. E., \& Amir, A. (2002). Surat Keterangan Syekh Jalaluddin trans. by Faqih Saghir. Kuala Lumpur: Dewan Bahasa dan Pustaka.

Onggang, P. M. (1964). Pongkinangolngolan Sinambela gelar Tuanku Rao: Terror Agama Islam Mazhab Hambali di Tanah Batak 1816-1833. Djakarta: Tandjung Pengharapan.

Syafnir Aboe Nain Dt. Kando Marajo, Nurmatias, E. (2009). Naskah Tuanku Imam Bonjol. Padang: Lembaga Kajian Paderi (1808-1838).

Vigelius. (1851). Fragmenten eener beschrijving van Sumatra's Westkust. 